\title{
The machine learning approach: Artificial intelligence is coming to support critical clinical thinking
}

\author{
Carmela Nappi, MD, ${ }^{\mathrm{a}}$ and Alberto Cuocolo, $\mathrm{MD}^{\mathrm{a}}$ \\ a Department of Advanced Biomedical Sciences, University Federico II, Naples, Italy
}

Received Jun 8, 2018; accepted Jun 8, 2018

doi:10.1007/s12350-018-1344-2

\section{See related article, pp. 147-155}

Machine learning is the area of computer science that takes advantage of computers to learn, from available information, interactions and trends of variables producing trustworthy and repeatable choices to guide decision making. ${ }^{1}$ This method seems very promising and suitable in clinical setting in response to the need of objective and standardized albeit personalized approaches. Therefore, several machine learning algorithms have been recently proposed to lead clinical management of patients with suspected or known coronary artery disease. $^{2,3}$

In the current issue of the Journal, Orozco et $\mathrm{al}^{4}$ evaluated the feasibility and performance of machine learning by considering clinical and functional variables of 1234 patients for the identification of subjects with impaired global and/or regional myocardial perfusion ratios at high risk of major cardiac events. For the machine learning model, 21 variables were considered, and a machine learning workflow was determined considering variables according to the information gain attribute ranking of each variable. The machine learning model was then constructed by means of a LogitBoost approach to adjust the relevance of weak variables and to obtain a single strong classifier. A tenfold cross-validation was finally applied to achieve stable and accurate estimates of the overall population. The machine learning algorithm for the

Reprint requests: Alberto Cuocolo, MD, Department of Advanced Biomedical Sciences, University Federico II, Via Pansini 5, 80131, Naples, Italy; cuocolo@unina.it

J Nucl Cardiol 2020;27:156-8.

1071-3581/\$34.00

Copyright (C) 2018 American Society of Nuclear Cardiology. identification of patients with myocardial ischemia showed a significantly higher area under curve compared to the one obtained with traditional logistic regression model $(0.72$ vs $0.61, P<.001)$. Similarly, the machine learning model for the identification of patients at high risk of major cardiac events showed a significantly higher area under curve compared to the one obtained by logistic regression model (0.71 vs $0.64, P<.001)$. The authors demonstrated the feasibility and applicability of such a method for the utilization of clinical and functional variables to identify patients at elevated risk of myocardial ischemia and/or major cardiac events suggesting to applying machine learning algorithm for optimization of diagnostic technique selection, cardiovascular diagnosis, and prognostic estimation, albeit further research is warranted.

After an initial successful application of machine learning algorithms into several economic and scientific areas, ${ }^{5}$ these methods are currently being considered in a number of biomedical fields. With regard to cardiovascular imaging, Han et $\mathrm{al}^{6}$ tested the incremental value of resting perfusion analysis by a machine learning approach over coronary stenosis by coronary computed tomography angiography (CCTA) for predicting significant ischemia as determined by fractional flow reserve. The results of their study demonstrated that machine learning-based prediction algorithms may identify ischemia with resting perfusion images in routine CCTA without additional procedures. ${ }^{6}$ Similarly, machine learning algorithms have been used for the detection and quantification of anatomic and physiologic atherosclerotic features detected on CCTA. ${ }^{7}$ By the same token, Alonso et $\mathrm{al}^{8}$ developed machine learning models to estimate a patient's risk of cardiac death based on adenosine myocardial perfusion imaging and associated clinical data. The authors compared the performance of this model to baseline logistic regression demonstrating a superior effectiveness of machine learning over 
logistic regression approach prediction of cardiac death event. This increasing interest in the integration of clinical data, CCTA and myocardial perfusion imaging findings to obtain a more consistent classifier is not surprising. A large body of literature researches have indeed demonstrated the importance of each test variable in specific patient category and the strong value of combined evaluation of clinical, functional, and structural abnormalities for appropriate risk stratification. ${ }^{9-17}$ Zampella et $\mathrm{al}^{18}$ recently demonstrated that the combined use of coronary calcium score, myocardial perfusion imaging, and quantitative coronary vascular function may help predict more accurately the presence of obstructive coronary artery disease with a significant net reclassification improvement of a model including coronary calcium score, ischemic total perfusion defect, and coronary flow reserve obtained by ${ }^{82} \mathrm{Rb}$ PET/CT compared to a model including only coronary calcium score and ischemic total perfusion defect. Therefore, machine learning algorithms seem to be a sophisticated implementation of traditional statistical and computational methods applied until today to learn from available data the lesson for the future. However, to wisely apply machine learning algorithms, imaging departments need large sets of data. In order to meet this specific need, a closer cooperation among different institutions is encouraged. On the other hand, data sharing among centers requires a high level of data uniformity. Thus, the application of machine learning algorithms could be not only an incentive for worldwide network building but also an additional motivation for global spread of standardized procedure of data collection translating into a more effective information source optimization.

It should be considered that human beings have inherited an immense wealth of knowledge and are now facing with the need to sort the labyrinth of complexity in certain belief to improve survival. As humanity has learned that all knowledge gained from the past is the only means of understanding the future, it is the advent of a new era where we are teaching machines that are our most valuable collaborators, to learn from the past and to predict the future. Nevertheless, it should be taken into account that beside the increasing research of objectivity for a decision making as much unbiased as possible, all the developed available artificial intelligence tools, must be supportive of the medical judgement and cannot replace critical clinician thinking.

\section{Disclosure}

C. Nappi and A. Cuocolo declare that they have no conflict of interest.

\section{References}

1. Deo RC. Machine learning in medicine. Circulation 2015;132:1920-30.

2. Betancur J, Otaki Y, Motwani M. Prognostic value of combined clinical and myocardial perfusion imaging data using machine learning. JACC Cardiovasc Imaging 2017. https://doi.org/10.1016/ j.jcmg.2017.07.024.

3. Arsanjani R, Dey D, Khachatryan T, Shalev A, Hayes SW, Fish $\mathrm{M}$, et al. Prediction of revascularization after myocardial perfusion SPECT by machine learning in a large population. J Nucl Cardiol 2015;22:877-84.

4. Juarez-Orozco LE, Knol RJJ, Sanchez-Catasus CA, MartinezManzanera O, van der Zant FM, Knuuti J. Machine learning in the integration of simple variables for identifying patients with myocardial ischemia. J Nucl Cardiol 2018. https://doi.org/10. 1007/s12350-018-1304-x.

5. Dunjko V, Briegel HJ. Machine learning and artificial intelligence in the quantum domain: A review of recent progress. Rep Prog Phys 2018. https://doi.org/10.1088/1361-6633/aab406.

6. Han D, Lee JH, Rizvi A, Gransar H, Baskaran L, SchulmanMarcus J, et al. Incremental role of resting myocardial computed tomography perfusion for predicting physiologically significant coronary artery disease: A machine learning approach. J Nucl Cardiol 2018;25:223-33.

7. Singh G, Al'Aref SJ, Van Assen M, Kim TS, van Rosendael A, Kolli KK, et al. Machine learning in cardiac CT: Basic concepts and contemporary data. J Cardiovasc Comput Tomogr 2018. https://doi.org/10.1016/j.jcct.2018.04.010.

8. Alonso DH, Wernick MN, Yang Y, Germano G, Berman DS, Slomka P. Prediction of cardiac death after adenosine myocardial perfusion SPECT based on machine learning. J Nucl Cardiol 2018. https://doi.org/10.1007/s12350-018-1250-7.

9. Cantoni V, Green R, Acampa W, Petretta M, Bonaduce D, Salvatore $\mathrm{M}$, et al. Long-term prognostic value of stress myocardial perfusion imaging and coronary computed tomography angiography: A meta-analysis. J Nucl Cardiol 2016;23:185-97.

10. Assante R, Zampella E, Arumugam P, Acampa W, Imbriaco M, Tout $\mathrm{D}$, et al. Quantitative relationship between coronary artery calcium and myocardial blood flow by hybrid ${ }^{82} \mathrm{Rb}$ PET/CT imaging in patients with suspected coronary artery disease. J Nucl Cardiol 2017;24:494-501.

11. Assante R, Acampa W, Zampella E, Arumugam P, Nappi C, Gaudieri V, et al. Coronary atherosclerotic burden vs coronary vascular function in diabetic and nondiabetic patients with normal myocardial perfusion: A propensity score analysis. Eur J Nucl Med Mol Imaging 2017;44:1129-35.

12. Assante R, Acampa W, Zampella E, Arumugam P, Nappi C, Gaudieri V, et al. Prognostic value of atherosclerotic burden and coronary vascular function in patients with suspected coronary artery disease. Eur J Nucl Med Mol Imaging 2017;44:2290-8.

13. Green R, Cantoni V, Petretta M, Acampa W, Panico M, Buongiorno $\mathrm{P}$, et al. Negative predictive value of stress myocardial perfusion imaging and coronary computed tomography angiography: A meta-analysis. J Nucl Cardiol 2017. https://doi.org/10. 1007/s12350-017-0815-1.

14. Nappi C, Nicolai E, Daniele S, Acampa W, Gaudieri V, Assante R, et al. Long-term prognostic value of coronary artery calcium scanning, coronary computed tomographic angiography and stress myocardial perfusion imaging in patients with suspected coronary artery disease. J Nucl Cardiol 2018;25:833-41.

15. Nappi C, Gaudieri V, Acampa W, Assante R, Zampella E, Mainolfi CG, et al. Comparison of left ventricular shape by gated 
SPECT imaging in diabetic and nondiabetic patients with normal myocardial perfusion: A propensity score analysis. J Nucl Cardiol 2018;25:394-403.

16. Gaudieri V, Nappi C, Acampa W, Zampella E, Assante R, Mannarino $\mathrm{T}$, et al. Added prognostic value of left ventricular shape by gated SPECT imaging in patients with suspected coronary artery disease and normal myocardial perfusion. J Nucl Cardiol 2017. https://doi.org/10.1007/s12350-017-1090-X.
17. Acampa W, Rozza F, Zampella E, Assante R, Mannarino T, Nappi $\mathrm{C}$, et al. Warranty period of normal stress myocardial perfusion imaging in hypertensive patients: A parametric survival analysis. J Nucl Cardiol 2018. https://doi.org/10.1007/s12350-013-9788-x.

18. Zampella E, Acampa W, Assante R, Nappi C, Gaudieri V, Mainolfi CG, et al. Combined evaluation of regional coronary artery calcium and myocardial perfusion by ${ }^{82} \mathrm{Rb} \mathrm{PET} / \mathrm{CT}$ in the identification of obstructive coronary artery disease. Eur $\mathrm{J}$ Nucl Med Mol Imaging 2018;45:521-9. 